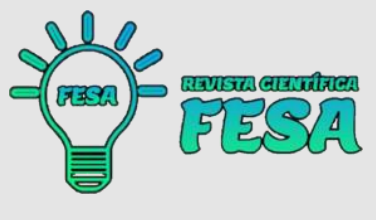

Jul. 2021

v. 1, n. $6,85-103$

ISSN: $2676-0428$

\title{
DIÁLOGOS PERTINENTES NA EDUCAÇÃO A DISTẦNCIA DIRETRIZES, PRINCÍPIOS E PRÁTICAS
}

\author{
Luciana Casagrande Aragão ${ }^{1}$
}

\begin{abstract}
RESUMO
Cada vez mais, constata-se que a educação a distância, com uso de tecnologia, tem proporcionado novas formas de relação para os professores, ao longo do percurso histórico e social, na tentativa de solução de lacunas formativas, apreensão de conhecimentos e maior agilidade no desenvolvimento de tarefas. Assim, este trabalho teve como objetivo central descrever diretrizes, princípios e práticas relacionadas à educação a distância por meio de diálogos reflexivos. O problema que fomentou este estudo foi a percepção que há muita ênfase na face prática da educação a distância, prescindindo-se do aprofundamento quanto aos seus princípios e suas as diretrizes. Dessa forma, espera-se que esses postulados bibliográficos possam estimular a criação de outros diálogos pertinentes a educação a distância no Brasil.
\end{abstract}

Palavras-chave: Educação a Distância; Práticas; Diretrizes.

\begin{abstract}
Increasingly, it is observed that distance education, using technology, has provided new forms of relationship for teachers, along the historical and social path, in an attempt to solve formative gaps, apprehension of knowledge and greater agility in the development of tasks. Thus, this work aimed to describe guidelines, principles and practices related to distance education through reflective dialogues. The problem that fostered this study was the perception that there is a lot of emphasis on the practical face of distance education, disregarding the deepening of its principles and guidelines. Thus, it is expected that these bibliographic postulates can stimulate the creation of other dialogues relevant to distance education in Brazil.
\end{abstract}

Keywords: Distance Education; Practices; Guidelines.

\section{RESUMEN}

Cada vez más, se observa que la educación a distancia, utilizando la tecnología, ha proporcionado nuevas formas de relación para los docentes, a lo largo de la trayectoria histórica y social, en un intento de resolver las brechas formativas, la aprehensión del conocimiento y una mayor agilidad en el desarrollo de las tareas. Así, este trabajo tuvo como objetivo describir pautas, principios y prácticas relacionadas con la educación a distancia a través de diálogos reflexivos. El problema que fomentó este estudio fue la percepción de que hay mucho énfasis en la cara práctica de la educación a distancia, sin tener en cuenta la profundización de sus principios y directrices. Así, se espera que estos postulados bibliográficos puedan estimular la creación de otros diálogos relevantes para la educación a distancia en Brasil.

Palabras clave: Educación a Distancia; Prácticas; directrices.

\footnotetext{
${ }^{1}$ Mestre em Ciências da Educação pela Universidad USAL - Argentina

Pedagogia - Supervisão Escolar

Diretora do Centro Estadual de Educação de Jovens e Adultos de Linhares.

centrolinhares@sedu.es.gov.br
}

\section{Multifaces do Conhecimento Científico: Teoria e Prática}




\section{INTRODUÇÃO}

Para melhor compreensão dos fenômenos que se referem às mudanças no contexto da sociedade atual e suas interrelações com as novas formas de ensino e aprendizagem, procuramos contextualizar alguns aspectos da sociedade atual.

A sociedade atual caracteriza-se pelas profundas transformações impulsionadas pelas inovações tecnológicas em diversas áreas. Os efeitos dessas transformações são perceptíveis em todos os setores da sociedade, tanto do ponto de vista econômico, quanto político, social e cultural.

A quantidade de informações é cada vez maior em função da presença maciça das Tecnologias da Informação e Comunicação (TIC). O acesso ao conhecimento encontra-se disponível para vários fins: informações, negócios, curiosidades que possibilitam a inovação, a interação, a troca e a pesquisa, ampliando as possibilidades de aquisição de conhecimento a uma velocidade em tempo real.

Desse modo, este artigo pretende descrever diretrizes, princípios e práticas relacionadas à educação a distância por meio de diálogos reflexivos. Para isso, serão aprofundadas as seguintes seções: Contribuições teóricas iniciais; Diretrizes, princípios e práticas de educação a distância; Conceituando a EAD e Educação a distância e globalização.

\section{CONTRIBUIÇÕES TEÓRICAS INICIAIS}

Levy S. Vygotsky é reconhecido como pioneiro da Psicologia do Desenvolvimento e traz contribuições para a compreensão adequada da relação entre aprendizagem e desenvolvimento, cuja teoria se transformou em um eixo articulador importante de cunho educacional. Sua perspectiva sócio-histórica baseia-se na tentativa de superar os reducionismos das concepções empiristas e idealistas. Assim, sua preocupação é encontrar metodologias de estudar o homem como um todo, membro da espécie humana e participante do processo histórico.

Neste sentido, os estudos de Vygotsky na perspectiva histórico-cultural foram assumidos como a base teórica deste estudo principalmente no que se refere ao conceito de ZDP (Zona de Desenvolvimento Proximal) que

\section{Multifaces do Conhecimento Científico: Teoria e Prática}




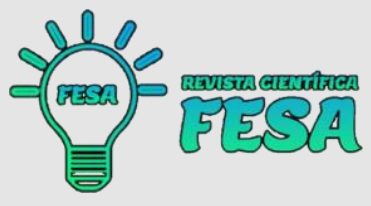

compreendemos se aplicar a formação do professor na modalidade a distância.

A citação abaixo pode bem expressar essa perspectiva:

Segundo Vygotsky (1998), o desenvolvimento de ações no nível social permite transformações cognitivas através da interação com a consequente reorganização e estruturação das ideias. A teoria sóciohistórica de Vygotsky enfatiza o processo de interação social, a colaboração entre os sujeitos no ambiente como uma ação imprescindível para a aprendizagem, pois expressa que a diversidade presente nos grupos auxilia o processo cognitivo, implícito nas formas de interação e comunicação (ALVES; CARLI, 2009 apud MOREIRA, 2010, p. 14).

Reconhecemos que a interação social e a colaboração a que se refere a citação são para ambientes presenciais de aprendizagem, porém podemos inferir que essa mesma perspectiva contribui quando nos referimos aos ambientes virtuais de formação de professores, por exemplo.

Assim, compreendemos que as ações de interagir, colaborar, compartilhar, presentes nos cursos de formação a distância podem ter como base a perspectiva histórico-crítica, assumida por Vygotsky (1998):

[...] estudar alguma coisa historicamente significa estudá-la no processo de mudança; esse é o requisito básico do método dialético". Para Vygotsky, somente por intermédio de um estudo histórico, é possível desvendar a natureza e a essência dos fenômenos psicológicos (VYGOTSKY, 1998, p. 85-86).

Neste sentido, reiteramos que investigar a relevância atribuída pelo professor à sua formação e as dificuldades encontradas na capacitação na modalidade a distância, implicará em adotar o conceito de "Zona de Desenvolvimento Proximal" (ZDP), assumido por Vygotsky (1998), pois tal conceito deixa claro que o desenvolvimento apresenta uma gênese social, isto é, se dá de fora para dentro, destacando a influência da cultura nesse processo.

Nessa concepção cria-se uma grande expectativa ao se trabalhar de forma grupal através da educação a distância, onde a cultura e os saberes adquiridos entre os participantes são muito ricos e tal modalidade acaba por influenciar que os participantes se conectem com educadores de todas as partes do Brasil e do mundo. Dessa forma, o diálogo, a troca de experiências e a interação entre os professores terão um papel importante a desempenhar no desenvolvimento de 
novas concepções onde a aprendizagem seja internalizada, completando 0 processo do interpessoal para o intrapessoal:

[...] a distância entre o nível de desenvolvimento real, que se costuma determinar através da solução independente de problemas, e o nível de desenvolvimento potencial, determinado através da solução de problemas sob a orientação de um adulto ou em colaboração com companheiros mais capazes (VYGOTSKY, 1984, apud LOURENÇO, 2008, p. 43).

Este ponto nos leva a confirmar que o investimento na capacitação de professores, na infraestrutura tecnológica e na estrutura organizacional é indispensável, tendo em vista as transformações rápidas e constantes que vêm ocorrendo no mundo contemporâneo, em consequência do aprimoramento acentuado da tecnologia, que exigem que os processos de formação sejam inovados, em especial aqueles que se vinculam ao sistema educacional. Para tanto, faz-se necessário que sejam oferecidas oportunidades para que tais saberes sejam compartilhados, no intuito de haver a construção de um conhecimento crítico-reflexivo:

Para que um experimento sirva como meio efetivo para estudar "o curso do desenvolvimento de um processo" ele deve oferecer o máximo de oportunidades para que o sujeito experimental se engaje nas mais variadas atividades que possam ser observadas, e não apenas rigidamente controladas. (VYGOTSKY, 1998, p. 16).

Desta forma, a possibilidade de criar Zonas de Desenvolvimento Proximal, nos percursos de formação de professores em ambientes virtuais traz à tona a necessidade de estimular uma gama de processos internos e trabalhar com funções e processos ainda não amadurecidos, mesmo pelo professor, o que podemos inferir que gera a necessidade dos gestores do programa de EAD, principalmente os tutores, munirem o professor (cursista) de um instrumento significativo na orientação de seu trabalho pedagógico, que é o aprender com o outro na perspectiva da interação:

O trabalho escolar com a ZDP tem relação direta com o entendimento do caráter social do desenvolvimento humano e das situações de ensino escolar, levando-se em conta as mediações histórico-culturais possíveis nesse contexto. Para Vygotsky, o aluno é capaz de fazer mais com o auxílio de uma outra pessoa (professores, colegas) do que faria sozinho; sendo assim, o trabalho escolar deve voltar-se especialmente para esta "zona" em que se encontram as capacidades 
e habilidades potenciais, em amadurecimento. Essas capacidades e habilidades, destaca o autor, uma vez internalizadas, tornam-se parte das conquistas independentes da criança (LOURENÇO, 2008, p. 44).

Compreendemos que a teoria histórico-cultural assumida por Vygotsky (1998) que descreve o papel do outro social no desenvolvimento dos que os rodeiam, parece feita à medida das necessidades apresentadas pelos educadores atualmente.

Por meio da introdução da ZDP, Vygotsky (1998) defende que o desenvolvimento de novos conhecimentos se dá através do convívio com pessoas que estão num patamar mais elevado, quanto ao grau de certos conhecimentos, e que podem colaborar para o amadurecimento também dos conhecimentos dos demais.

Nesse contexto, o "bom ensino" para Vygotsky (1998) é aquele que se adianta ao desenvolvimento e este ensino sempre será disponibilizado por meio de demonstração, assistência, fornecimento de pistas, instruções, entre outras formas de apoio. E isso não é diferente na educação a distância. Esse "bom ensino" se materializa, na educação a distância, por meio das equipes de apoio, dos tutores presencial e a distância, das ferramentas online, seu design, dos tutoriais, entre outros, mas sobretudo pelas possibilidades asseguradas de trocas entre os cursistas por meio dos Fóruns.

Sendo a capacitação a distância uma ação comprometida, que exige trocas de experiências da prática pedagógica dos professores e onde são expostas as metodologias utilizadas, sempre com a tutoria de um mediador, possivelmente haverá o enriquecimento e amadurecimento dos conhecimentos dos participantes se os conceitos da teoria em questão forem assumidos. Essa mesma compreensão pode ser assumida no que tange a prática pedagógica dos professores alunos dos cursos na modalidade a distância. Lourenço (2008) traz uma das contribuições de Vygotsky (1998) sobre esta questão:

De acordo com a teoria de Vygotsky, todo sujeito é um ser ativo em seu processo de aprendizado e desenvolvimento, pois é ele quem age sobre o instrumento mediador de sua ação. O computador representa hoje uma nova ferramenta mediadora e o aluno, enquanto aprendiz, precisa estar apto a interagir com o mesmo, dominar suas funções, signos e sistemas de símbolos para que a sua conduta seja consciente e planejada. (LOURENÇO, 2008, p. 47).

\section{Multifaces do Conhecimento Científico: Teoria e Prática}




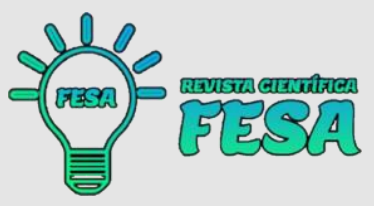

Assim, um professor reflexivo, consciente e crítico será capaz de compreender, por exemplo, a influência da tecnologia no mundo moderno e colocá-la a serviço da educação e da formação de seus alunos, onde também se apropriará da ZDP para auxiliá-los na construção do conhecimento. Esse é o nosso ponto de partida para analisarmos o discurso dos professores referentes à sua formação na modalidade a distância e a influência desta formação na prática pedagógica às diferentes áreas de conhecimento.

Outro conceito apresentado por Vygotsky (1998), e de grande importância, é o de internalização que consiste na reconstrução interna de uma operação externa. Tal processo de internalização se apresenta a partir de uma série de transformações, segundo Vygotsky (2007). A primeira delas se refere a uma operação que inicialmente representa uma atividade externa, que é reconstruída e começa a ocorrer internamente; a segunda se refere a um processo interpessoal e que é transformado num processo intrapessoal e a terceira se refere à transformação de um processo interpessoal num processo intrapessoal que resulta de uma série de eventos ocorridos ao longo do desenvolvimento.

Nesse processo de internalização, as transformações que se sucedem, também, são aplicáveis ao contexto virtual de aprendizagem. E elas são indutoras de inúmeras outras transformações nos sujeitos em desenvolvimento, quer sejam crianças ou mesmo adultos, desde que estes se proponham ou se coloquem no lugar de desenvolvimento e aprendizagem contínuos.

Ainda, assentada na perspectiva sócio-histórico-cultural, trazemos outros colaboradores do trabalho de Vygotsky, com destaque para Leontiev e Luria os quais desenvolveram a Teoria da Atividade. Essa teoria discrimina alguns processos relacionados com a mediação entre um sujeito e um objeto para obter um determinado resultado e precisar o conceito de atividade.

Segundo Leontiev (1992) as atividades seriam processos psicologicamente caracterizados por aquilo a que o processo, como um todo, se dirige (seu objeto), coincidindo sempre com o objetivo que estimula o sujeito a executar esta atividade, isto é, o motivo (LEONTIEV, 1992, p. 68).

De acordo com Leontiev (1992) apud Nobre (2013, p. 45): 
Uma atividade é composta por ações e operações. Uma atividade para que ocorra pode depender da execução de diferentes ações e uma mesma ação pode ser executada em mais de uma atividade. Participar de uma atividade é realizar ações com objetivos definidos. As operações consistem em rotinas bem definidas, usadas diante de certas condições na realização de uma ação. Cada ação internalizada (inconsciente) passa a ser considerada uma operação. A atividade ocorre mediante um motivo que consiste no objeto em transformação, na busca pelo resultado, as ações são orientadas às metas e as operações orientadas a condições (LEONTIEV, 1992 apud NOBRE, 2013, p. 45).

Essa atividade, a qual se refere Leontiev (1992), possui três elementos: sujeito, objeto e ferramenta de mediação. Nesse triângulo, o sujeito é o agente que atua sobre o objeto da atividade e o objeto é o elemento para o qual as ações da atividade estarão direcionadas. O relacionamento recíproco entre o sujeito e o objeto da atividade sempre será mediado por uma ou mais ferramentas (também chamadas de artefatos de mediação), que podem ser instrumentos, sinais, procedimentos, máquinas, métodos, leis, formas de organização de trabalho (NOBRE, 2013). Em nosso olhar, essa perspectiva teórica se aplica à estrutura e realidade vivenciada na educação a distância, uma vez que os arte fatos de mediação também estão presentes em toda a proposta, quer seja em cursos de aperfeiçoamento, quer sejam em cursos de graduação. O grande diferencial, nesse contexto, são as pessoas, atores centrais do processo de mediação.

Finalmente destacamos um brasileiro, como grande representante da perspectiva teórica sociocultural que é Paulo Freire (1996). A grande ênfase, em suas obras, é dada aos aspectos sócio-político culturais, sobretudo por ter se dedicado à educação popular e a alfabetização de adultos.

A forma de nos colocarmos junto ao outro, de mediarmos o conhecimento e de intervirmos nos contextos nos quais atuamos, fala de uma concepção assumida não apenas pedagogicamente, mas de uma concepção ligada à dimensão humana, por meio da qual estabelecemos a diferença em nossas relações no mundo. Nesse sentido:

O professor que pensa certo deixa transparecer aos educandos que uma das bonitezas de nossa maneira de estar no mundo e com o mundo, como seres históricos, é a capacidade de, intervindo no mundo, conhecer o mundo. Mas, histórico como nós, o nosso conhecimento do mundo tem historicidade (FREIRE, 1996, p. 14).

\section{Multifaces do Conhecimento Científico: Teoria e Prática}




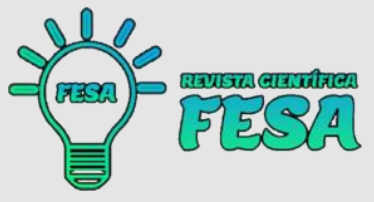

A reflexão de Freire (1996) nos fala da existência de homens concretos, situados no tempo e espaço, num "diálogo" permanente com os contextos sociais, econômicos, culturais e, sobretudo políticos, constituindo, desse modo, o contexto histórico. E nessa concretude, a verdadeira educação, segundo Freire (1996), é a que problematiza e ajuda a superar a relação opressor-oprimido (MIZUKAMI, 1986, p. 97). Assim, cabe ao professor, "Saber que ensinar não é transferir conhecimento, mas criar as possibilidades para a sua própria produção ou a sua construção" (FREIRE, 1996, p. 21).

Essa ideia confere uma grande potência aos processos de ensino, aprendizagem e avaliação nas relações estabelecidas na educação distância, uma vez que a curiosidade epistemológica, a criatividade e a inventividade podem e devem ser valorizadas, poisa centralidade do processo educativo não está exclusivamente nas mãos do professor.

Sobre a curiosidade, Freire (1996) escreve que é ela que nos move e nos inquieta, possibilitando-nos buscar, construir e produzir conhecimento. $\mathrm{Na}$ prática, isso equivale à “[...] capacidade crítica de 'tomar distância' do objeto, de observá-lo, de delimitá-lo, de cindi-lo, de 'cercar' o objeto ou fazer sua aproximação metódica, sua capacidade de comparar, de perguntar" (FREIRE, 1996, p. 33).

A abordagem sociocultural nos interessa, enquanto aporte teórico central nessa pesquisa, devido à ênfase dada à interação do sujeito com o meio, com a sua realidade e com o outro, tendo a perspectiva da mediação como elemento imprescindível nas relações de aprendizagem e desenvolvimento humano.

É no processo de mediação e, também, de valorização da "curiosidade epistemológica", conceito usado, tanto pelos alunos quanto por professores, que a inquietação, a busca pelo conhecimento com base no estímulo à reflexão, ao diálogo, à cooperação, à busca de solução em conjunto entre outros (NOBRE, 2013), que a atividade docente de puro vai-e-vem de perguntas e respostas, deixa de existir, pois a ênfase recai no processo de dialogicidade. Mas é preciso destacar, quanto à dialogicidade, segundo Freire (1996), que ela: 
[...] não nega a validade de momentos explicativos, narrativos em que o professor expõe ou fala do objeto. O fundamental é que professor e alunos saibam que a postura deles, do professor e dos alunos, é dialógica, aberta, curiosa, indagadora e não apassivada, enquanto fala ou enquanto ouve. O que importa é que professor e alunos se assumam epistemologicamente curiosos (FREIRE, 1996, p. 33).

Finalmente, concordamos com Nobre (2013, p. 48) que o aporte teórico da abordagem sócio-histórico-cultural, nos permite partir dos saberes dos professores e nas relações construídas no contexto da modalidade a distância é que se estabelecem novos aprendizados e possibilidades de novas apropriações.

Nesse sentido vale lembrar a conceituação dada por Mizukami (1986, p. 87) ao contexto cultural, fundamental à compreensão dessa abordagem, assim entendido, como tudo aquilo que "[...] constitui a aquisição sistemática da experiência humana, aquisição esta que será crítica e criadora e não simplesmente armazenamento de informações justapostas, que não foram incorporadas ao indivíduo total". Com igual importância e fundamental o contexto histórico, segundo a mesma autora, consiste no conjunto das "[...] respostas dadas pelo homem à natureza, aos outros homens, às estruturas sociais, e na sua tentativa de ser progressivamente cada vez mais o sujeito de sua práxis, ao responder aos desafios de seu contexto". Nesse sentido, concordamos com Freire (2003, p. 43) quando escreve que conhecer é tarefa de sujeitos, não de objetos. E é como sujeito e somente enquanto sujeito, que o homem pode realmente conhecer.

\section{DIRETRIZES, PRINCÍPIOS E PRÁTICAS DE EDUCAÇÃO A DISTÂNCIA}

A Educação a distância é uma modalidade diferenciada do modelo tradicional de educação (presencial), que obriga aluno e professor a estarem em um mesmo espaço físico (a sala de aula) para a concretização do processo de ensino e aprendizagem, pois propõe uma metodologia inovadora onde aluno e professor utilizam tecnologias da informação para a realização do processo educacional, estando em espaços e tempos diferentes.

Essa modalidade de educação permite um atendimento mais individualizado, oferecendo aos discentes mecanismos para que estes possam se manifestar, principalmente, através dos recursos da Tecnologia da

\section{Multifaces do Conhecimento Científico: Teoria e Prática}




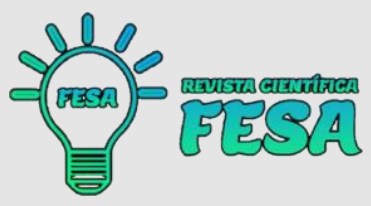

Informação e da Comunicação (TIC) e por meio do Ambiente Virtual de Aprendizagem (AVA).

A EAD tem se expandido de forma vertiginosa nas diversas instituições, tanto no sistema formal como no não formal. $\mathrm{Na}$ área educacional, a sua expansão ocorreu de forma mais marcante nos cursos de graduação e de pósgraduação.

No cenário brasileiro, o foco da política educacional centra-se na defesa de uma educação superior para todos. E neste sentido a EAD possibilita atingir grande contingente de pessoas, principalmente com a evolução das tecnologias de informação e comunicação e o advento da internet.

Cortelazzo (2009, p. 9) esclarece que:

[...] A sociedade brasileira assiste a uma revolução no acesso de milhões de pessoas às TICs impostas pela economia, chamada [...] de sociedade do conhecimento. Ao mesmo tempo, o acesso à educação superior se torna uma obrigação para se conseguir trabalho nessa mesma economia que exige competências diferenciadas dos profissionais e acirra a competição pelas vagas existentes. $O$ preço de entrada [...] é o da educação (CORTELAZZO, 2009, p. 9).

Discorrendo sobre a EAD, Litwin (2001, p. 13) esclarece que:

O traço distintivo da modalidade consiste na mediatização das relações entre os docentes e os alunos. Isso significa, de modo essencial, substituir a proposta de assistência regular à aula por uma nova proposta na qual os docentes ensinam e os alunos aprendem mediante situações não convencionais, ou seja, em espaços e tempos que não compartilham (LITWIN, 2001, p. 13).

No Brasil, o ensino a distância se faz presente pela primeira vez no texto de uma Lei de Diretrizes e Bases da Educação Nacional, em 1996, quando é promulgada a Lei oㅜ 9.394 .

\section{CONCEITUANDO A EAD}

De acordo com Nunes (1997), o termo Educação a Distância, apresenta diferentes denominações, de acordo com a prática de cada país: educação por correspondência, no Reino Unido; estudo em casa (home study), nos EUA; estudos externos (external studies), na Austrália; educación a distancia, em espanhol; e tele-educação, em português.

\section{Multifaces do Conhecimento Científico: Teoria e Prática}




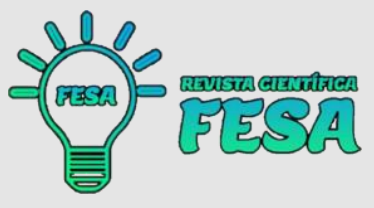

Em países extensos como o Brasil, os cursos nessa modalidade de ensino têm um papel importante, pois, na maioria das vezes, são as únicas formas de educação disponível para a população que vive em locais isolados e de difícil acesso, ou para os que se encontram em prisões, hospitais ou instituições similares (ARAUJO; FREITAS, 2005, p. 59).

$\mathrm{Na}$ atualidade, coexistem no Brasil as seguintes modalidades: a educação presencial, semipresencial (parte presencial/parte virtual ou a distância) e educação a distância (ou virtual). A presencial refere-se a cursos regulares em qualquer nível de ensino, nos quais professores e alunos se encontram sempre em um local físico, chamado sala de aula. A semipresencial é a que ocorre parte na sala de aula e outra parte a distância, com uso de tecnologias.

A educação a distância pode ocorrer nos mesmos níveis do ensino regular, tanto no Ensino Fundamental, Médio, Superior e na Pós-graduação. Entretanto, ela é mais adequada para a educação de adultos, uma vez que requer aprendizagem individual e habilidades de pesquisa, como acontece no ensino de graduação e pós-graduação.

Independente das diversas denominações, a educação a distância se apresenta hoje como uma importante alternativa no combate às distorções provocadas pela incapacidade dos sistemas tradicionais de ensino presencial de atender às demandas cada vez mais crescentes pela formação continuada, e depende, cada vez mais, dos meios tecnológicos da informação e da comunicação.

Para Niskier (1999), a Educação a Distância é uma modalidade que se afirma cada vez mais como uma tecnologia, a tecnologia da esperança. $O$ argumento central é o de que, com a expansão das tecnologias da informação e da comunicação, ampliou-se a noção de ensino, que hoje não se restringe apenas à precária sala de aula presencial.

Bandeira, citando Nunes (2007, p. 48), afirma que a EAD é norteada por princípios, como:

[...] flexibilidade, permitindo mudanças do processo, não só para os professores, mas também para os alunos; contextualização, satisfazendo com rapidez demandas e necessidades educativas ditadas por situações sócioeconômicas específicas de regiões ou localidades; diversificação, gerando atividades e materiais que 
permitam diversas formas de aprendizagem; abertura, permitindo que o aluno administre o tempo e espaço próprios (NUNES, 2007, p. 48).

Esses princípios representam a ruptura de paradigma com a modalidade presencial e apontam para o caráter democratizante da EAD, e, de acordo com Bandeira (2007, p. 49) essa modalidade caracteriza-se pela possibilidade de uso de vários meios de comunicações, recursos tecnológicos e capacidade de modelagem em função dos interesses manifestos pelo público interessado.

Existem vários conceitos de Educação a Distância e todos apresentam alguns pontos em comum. Entretanto, cada autor ressalta alguma característica em especial na sua conceitualização. Moran (2002, p. 1), afirma que:

A educação a distância pode ter ou não momentos presenciais, mas acontece fundamentalmente com professores e alunos separados fisicamente no espaço e/ou no tempo, mas podendo estar juntos através de tecnologias de comunicação (MORAN, 2002, p. 1).

Rodrigues (1999, p. 1) afirma, ainda, que a Educação a Distância:

[...] é um sistema tecnológico de comunicação bidirecional que pode ser massivo e que substitui a interação pessoal na sala de aula entre professor e aluno como meio preferencial de ensino pela ação sistemática e conjunta de diversos recursos didáticos e o apoio de uma organização e tutoria que propiciam uma aprendizagem independente e flexível (RODRIGUES, 1999, p. 1).

Peters, citando Nunes (1992, p. 89), realiza uma crítica ao afirmar que "a Educação a Distância é uma forma industrializada de ensinar e aprender", e, atribuindo ênfase a metodologia, enfatiza que:

\begin{abstract}
Educação/ensino a distância (Fernunterricht) é um método racional de partilhar conhecimento, habilidades e atitudes, através da aplicação da divisão do trabalho e de princípios organizacionais, tanto quanto pelo uso extensivo de meios de comunicação, especialmente para o propósito de reproduzir materiais técnicos de alta qualidade, os quais tornam possível instruir um grande número de estudantes ao mesmo tempo, enquanto esses materiais durarem. É uma forma industrializada de ensinar e aprender (NUNES, 1992, p. 89).
\end{abstract}

Moore (1973, p. 37) destaca que as ações do professor e a comunicação deste com os alunos devem ser facilitadas: 
Ensino a distância pode ser definido como a família de métodos instrucionais onde as ações dos professores são executadas à parte das ações dos alunos, incluindo aquelas situações continuadas que podem ser feitas na presença dos estudantes. Porém, a comunicação entre o professor e o aluno deve ser facilitada por meios impressos, eletrônicos, mecânicos ou outro (MOORE, 1973, p. 37).

Nunes (1992, p. 17) enfatiza a diversidade das formas de estudo, para ele:

O termo Educação a Distância esconde-se sob várias formas de estudo, nos vários níveis que não estão sob a contínua e imediata supervisão de tutores presentes com seus alunos nas salas de leitura ou no mesmo local. A Educação a Distância beneficia-se do planejamento, direção e instrução da organização do ensino (NUNES, 1992, p. 17).

Moran (2005, p. 9) afirma, por fim, que:

Educação a distância é o processo de ensino-aprendizagem, mediado por tecnologias, no qual professores e alunos estão separados espacial e/ou temporalmente. Apesar de não estarem juntos, de maneira presencial, eles podem estar conectados, interligados por tecnologias, principalmente as telemáticas, como a Internet. Mas também podem ser utilizados o correio, o rádio, a televisão, o vídeo, o CD-ROM, o telefone, o fax e tecnologias semelhantes (MORAN, 2005, p. 9).

Segundo a Universidade de Wisconsin, Educação a Distância é uma experiência de ensino e aprendizagem planejada que usa uma variedade de tecnologias, sendo desenhada para encorajar a interação com os alunos e comprovar o aprendizado (TRIPATHI, 1997).

Após o advento da Lei de Diretrizes e Bases da Educação Brasileira (n. 9394/96), define-se a Educação a Distância como:

[...] Uma forma de ensino que possibilita a autoaprendizagem, com a mediação de recursos didáticos sistematicamente organizados, apresentados em diferentes suportes de informação, utilizados isoladamente ou combinados, e veiculados, pelos diversos meios de comunicação (Art. 1ํ do Decreto Lei n.2494, que regulamenta o Art. 80 da LDB) (BRASIL, 1996).

De acordo com essa Lei:

[...] Caracteriza-se a educação a distância como uma modalidade educacional na qual a mediação didático-pedagógica nos processos de ensino e aprendizagem ocorre com a utilização de meios e tecnologias 
de informação e da comunicação, com estudantes e professores desenvolvendo atividades educativas em lugares ou tempos diversos. (Art. 1ํ) (BRASIL, 1996).

Essas definições destacam as características principais da EAD, diferenciando-a do ensino presencial. Para Moore e Kearsley (1996, p. 206), seis elementos são essenciais para uma clara definição:

[...] separação entre professores e alunos; uso de meios técnicos mídia, com possibilidades de atividades variadas, como seminários presenciais ou via broadcasting; estabelecimento de uma comunicação bidirecional, por meio de recursos didáticos e tecnológicos; comunicação predominantemente assíncrona entre professores e alunos; organização educacional, com planejamento e preparação de materiais didáticos produzidos especialmente para essa modalidade de ensino e aprendizagem, visando ao autoaprendizado dos alunos; estabelecimento de soluções interativas que visem a proximidade $\mathrm{e}$ afetividade entre alunos e professores (MOORE, KEARSLEY; 1996, p. 206).

Essa modalidade de ensino e aprendizagem deve oferecer suporte técnico e metodológico, estruturando um sistema que viabilize e incentive a autonomia dos estudantes nos processos de aprendizagem. Pressupõe a capacidade do estudante construir o conhecimento por si mesmo, tornando-se autodidata, adotando atitudes e habilidades como a realização de estudo individualizado, independente e flexível, tornando-se ator e autor de suas práticas e reflexões.

\section{EDUCAÇÃO A DISTÂNCIA E GLOBALIZAÇÃO}

Uma das características da globalização, principalmente com o advento da internet, é a comunicação e a disseminação das informações em tempo real, atravessando fronteiras, encurtando distâncias e redimensionando as noções de tempo e espaço. Países e pessoas encontram-se interconectados em uma rede mundial, produzindo e reproduzindo cultura. Essa rede possibilita e fortalece a $E A D$, criando oportunidades de acesso e democratização do saber, ou seja, a globalização nas áreas da economia, da cultura e das comunicações rompe barreiras e cria novos mercados (CORTELAZZO, 2009, p. 47).

De acordo com Demo (1998, p. 5), um dos traços mais fortes da globalização é a intensividade do conhecimento. $O$ que mais facilmente se globaliza é a tecnologia. Cortelazzo (2009) afirma que a globalização leva, de 


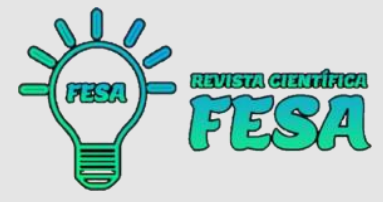

fato, a interpretar a educação como um fenômeno que dura a vida toda e que vai para além da escola e da formação profissional.

A Educação a Distância - EAD, também conhecida por EAD Online, teleducação, ou e-learning, caracteriza-se por ser um processo de ensino e aprendizagem mediado por tecnologias, em que professores e alunos encontram-se separados espacial ou temporalmente. O advento das tecnologias alavancou essa modalidade de ensino, facilitando a interação e a interlocução entre os envolvidos no processo.

No Brasil a EAD é conhecida, como Ensino a Distância, Treinamento a Distância, ou mesmo Educação online, este último, um conceito mais restrito da EAD, e que, segundo Moran (2002, p. 41) é o conjunto de ações de ensinoaprendizagem desenvolvidas por meio de meios telemáticos, como a internet, a videoconferência e a teleconferência. A expressão e-learning é uma forma utilizada para expressar a EAD fora e dentro do país.

Nessa modalidade, discute-se, inclusive, o termo a distância, uma vez que com o uso de tantos recursos tecnológicos disponíveis a partir do advento da internet, dos satélites e das redes sociais, a distância não pode se referir a uma simples questão física ou geográfica.

Inicialmente a EAD foi considerada uma solução paliativa para déficits educacionais, visando suprir uma lacuna:

[...] quando o sistema educacional convencional falhava em proporcionar escolaridade mínima a uma parcela significativa da população. Com isso, a sociedade se acostumou a olhar para a EAD como uma educação de "segunda categoria" a ser utilizada especialmente por aqueles que não tiveram oportunidade de uma educação presencial convencional (AZEVEDO, 2013, p. 62).

Entretanto, nas últimas décadas ela se firmou como modalidade regular e efetiva de educação, principalmente com a introdução de recursos tecnológicos e com o advento da internet, permitindo uma maior flexibilização de acesso, currículos e metodologias (BELLONI, 2002). Em um país com dimensões territoriais como o Brasil, a EAD assume um importante papel na democratização do ensino.

A EAD está se expandindo, e afetando profundamente a educação. Em um mundo conectado em redes, caracterizado pela mobilidade e flexibilidade, a 


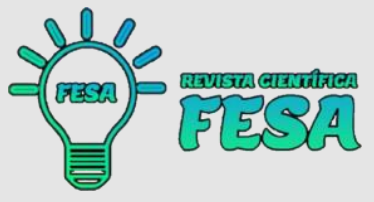

Jul. 2021

v. 1, n. $6,85-103$

ISSN: $2676-0428$

educação a distância passou de uma modalidade complementar para se constituir em eixo norteador das mudanças profundas da educação como um todo, principalmente no ensino superior. Entretanto, as instituições formadoras de profissionais da Educação não estão atentas a estas mudanças e continuam preparando os professores para uma escola tradicional, do passado, sem utilização dos recursos em rede e sem desenvolver as competências digitais.

$\mathrm{Na}$ última década as produções de artigos, livros, congressos e seminários, relativos a Educação a Distância cresceu substancialmente como modalidade utilizada na formação e capacitação de professores. O mesmo ocorre com outros temas afins, como: os Ambientes Virtuais de Aprendizagem (AVA), as novas formas de comunicação e interação nos ambientes virtuais, novas metodologias de ensino e utilização de materiais didáticos específicos para a EAD, entre outros:

No mundo inteiro as instituições de ensino estão procurando se informar e acompanhar essa verdadeira revolução educacional que está acontecendo, inclusive e especialmente as mais tradicionais instituições de EAD. A chamada educação online está desafiando estas instituições a repensarem seus modelos pedagógicos ao mesmo tempo em que oferece soluções para problemas com estas mesmas instituições vem se confrontando cada vez mais com, à medida que passamos de uma sociedade industrial para uma sociedade da informação (AZEVEDO, 2013, p. 78).

As duas modalidades de educação: presencial e a distância possuem suas especificidades em termos de concepção, recursos, interações, entre outras, que devem ser levados em consideração. Da mesma forma que não se admite simplesmente transpor os conteúdos de um curso presencial para um curso a distância, deve-se ter o mesmo cuidado em relação à formação dos professores para a modalidade EAD.

Podemos inferir desta discussão, que os cursos a distância vêm sendo adotados nas últimas décadas, no entanto, a adoção dessa modalidade parece não ter sido acompanhada das necessárias mudanças tanto na infraestrutura humana e tecnológica, como no desenvolvimento de pesquisas sobre viabilidades, potencialidades e limites da EAD. Nas palavras de Belloni (2008, p. 3): 
A educação aberta e a distância aparece cada vez mais, no contexto das sociedades contemporâneas, como uma modalidade de educação extremamente adequada e desejável para atender às novas demandas educacionais decorrentes das mudanças na nova ordem econômica mundial (BELLONI, 2008, p. 3).

Dessa forma, a inserção dos professores na Educação a Distância necessita atenção e empenho das equipes que elaboram e desenvolvem os cursos e das equipes de apoio e tutoria, para que os professores se sintam orientados e motivados a participarem.

Portanto, no contexto das mudanças causadas pela globalização da economia, a profissão docente também passa por modificações, impondo a incorporação de habilidades e competências para lidar com as TICs. A necessidade de permanente atualização é a tônica da sociedade globalizada, que requer de qualquer profissão, novas formas de aprender, que possibilitem o exercício da atividade profissional de acordo com as novas exigências do mundo do trabalho.

\section{CONSIDERAÇÕES FINAIS}

A EAD altera a dinâmica da relação entre professores e alunos, e uma série de características da educação presencial se perde, como a linguagem nãoverbal e a capacidade de identificação entre os sujeitos envolvidos. Assim, os professores ou mediadores precisam se atentar para esses elementos que interferem no processo de ensino e aprendizagem, utilizando adequadamente os recursos disponíveis nessa modalidade.

Além disso, essa modalidade de ensino e aprendizagem altera as noções de tempo e espaço da docência, não apenas devido o afastamento físico do professor e do aluno, mas, também, em função do afastamento temporal entre planejamento e execução do processo de ensino e de aprendizagem, isto é, do pensar e do fazer da prática docente.

A escola pode e deve ter outra função, além de garantir, apenas, a universalização de acesso. É preciso que ela assuma a função de universalizar o conhecimento e a informação. Nessa perspectiva, as TICs desempenham um papel importante neste processo. Entretanto, conforme nos lembra Pretto (2013), não basta a implantação de novos recursos tecnológicos nas escolas, como 


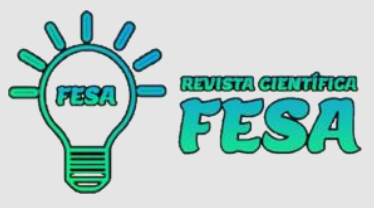

garantia de que se está fazendo uma nova educação, pois a incorporação das TICs ocorre, na maioria das vezes, de forma instrumental, com uso de velhas práticas educativas, que não propiciam a efetiva integração entre a educação e a comunicação. Precisamos, portanto, ficar atentos, pois, a mudança de paradigmas requer um cuidado maior com a formação de professores.

\section{REFERÊNCIAS BIBLIOGRÁFICAS}

ARAUJO, B.; FREITAS, K. S. de. Educação a Distância no contexto brasileiro: a experiência da UFBA. Salvador: PROGED/ISP, 2005.

ARAUJO, B.; FREITAS, K. S. de. Educação a Distância no contexto brasileiro: experiências em formação inicial e continuada. Salvador: PROGED/ISP, 2007.

AZEVEDO, Wilson. Panorama atual da Educação a Distância no Brasil. Disponível em: http://escolanet.com.br/sala_leitura/txt_integral.html. Acesso em: 22 set. 2013.

BELLONI, M. L. Educação a distância. 5. ed. Campinas: Autores Associados, 2008.

BELLONI, M. L. Ensaio sobre a Educação a distância no Brasil. Educação \& Sociedade, [Campinas], v. 23, n. 78, p. 117-142, abr. 2002.

BRASIL. Congresso Nacional. Lei Federal 9394 de 20 de dezembro de 1996. Estabelece Diretrizese Bases da Educação Nacional. Brasília, 1996.

CAZAROTO, C. Formando Professores a Distância:Estudo do Livro Base para o Ensino de Língua Portuguesa no Curso Normal Superior - UEM (1 $1^{\text {a }}$ Turma). Dissertação de Mestrado em Letras. Paraná: UFM, 2007. Disponível em: http://www.ple.uem.br/defesas/pdf/ccazaroto.pdf. Acesso em: 21 nov. 2014.

FREIRE, P. Pedagogia da Autonomia: Saberes Necessários à Prática Educativa. 23. ed. Rio de Janeiro: Paz e Terra, 1996.

FREIRE, P. A Educação como Prática da Liberdade. 23. ed. Rio de Janeiro: Paz e Terra, 1999.

LEONTIEV, A. N. Uma contribuição à teoria do desenvolvimento da psique infantil. In: VIGTOSKY, L. S.; LURIA, A. R.; LEONTIEV, A. N. Linguagem, desenvolvimento e aprendizagem. São Paulo: Ícone, 1992. p. 59-68.

MIZUKAMI, M. G. N. Ensino, as abordagens do processo. São Paulo: EPU, 1986.Dissertação (Mestrado)-Programa de Pós-gradualção em educação. Universidade /Federal do Espírito Santos-UFES, Vitória, 2012. 
MOORE, M.; KEARSLEY, G. Educação a Distância: uma visão integrada. São Paulo: Cengage Learning, 2008.

MORAN, J. M. Novos caminhos do ensino a distância. Informe CEAD -Centro de Educação a distância - SENAI, R. J., v. 1, n.5, p. 1-3, out./dez. 2002. Disponível em: http://www.eca.usp.br/prof/moran/dist.htm. Acesso em: 5 jun. 2013.

MORAN, J. M. A educação que desejamos: Novos desafios e como chegar lá. Campinas, SP: Papirus, 2009.

NISKIER, A. Educação a Distância: a tecnologia da esperança. São Paulo: Loyola, 1999.

NOBRE, I. A. M. Docência coletiva: saberes e fazeres na educação a distância. Tese (Doutorado) - Programa de Pós-gradualção em educação. Universidade /Federal do Espírito Santos-UFES, Vitória, 2013.

NUNES, V. B. Processo Avaliativo de Tutores a Distância em um Curso de Pós-graduação e Reflexões sobre Mudanças de Condutas. Tese de Doutorado. Vitória: Programa de Pós-graduaçãoem Educação da Universidade Federal do Espírito Santo UFES, 2012.

VYGOTSKY, L. S. A formação social da mente. Trad. DeJosé Cipolla Neto. 6. ed. São Paulo: Martins Fontes, 2003.

VYGOTSKY, L. S. Pensamento e linguagem. 2. ed. Tradução de Jeffderson Luiz Camargo. São Paulo: Martins Fontes, 1998. 